\title{
United States faces dentist shortage
}

Published at www.cmaj.ca on Oct. 21

$\mathrm{R}$ esidents of the United States who need teeth extracted may soon have to do it the oldfashioned way - with pliers, whisky and elbow grease - because there may not be enough dentists to go around.

The number of practising dentists is projected by the American Association of Dental Schools to start declining in 2014, which will likely exacerbate an existing problem: the unwillingness of many to practice in rural areas. Further compounding the problem are such factors as a continuing migration from general practice to specialties like orthodontics, the closure of dental schools, a decrease in the size of graduating classes, the forthcoming mass retirement of older dentists and the growing number of female dentists, who tend to work fewer hours than their male colleagues.

In the 1982-83 academic year, the US produced 5756 new dentists, according to the American Dental Association. Over the following 25 years, the US population increased by almost a third, but the number of dental school graduates decreased, falling to 4700 by 2007 . There are also fewer US dental schools (58, compared to 60 in 1980), and those that remain open have seen their class sizes shrink.

Unlike medical students, who obtain clinical experience in teaching hospitals, dentists-in-training obtain their practical skills at expensive, university-run clinics. And these clinics are getting more and more costly to operate. In fact, it cost more than twice as much to run such a clinic in 2001 as it did in 1991 ( $J$ Dent Educ 2006;70:921-4). As a result, several prestigious universities have abandoned dental education altogether. Georgetown University, in Washington, DC, closed its 86-year-old dental school in 1987. In 2001, Northwestern University in Evanston, Illinois, shut

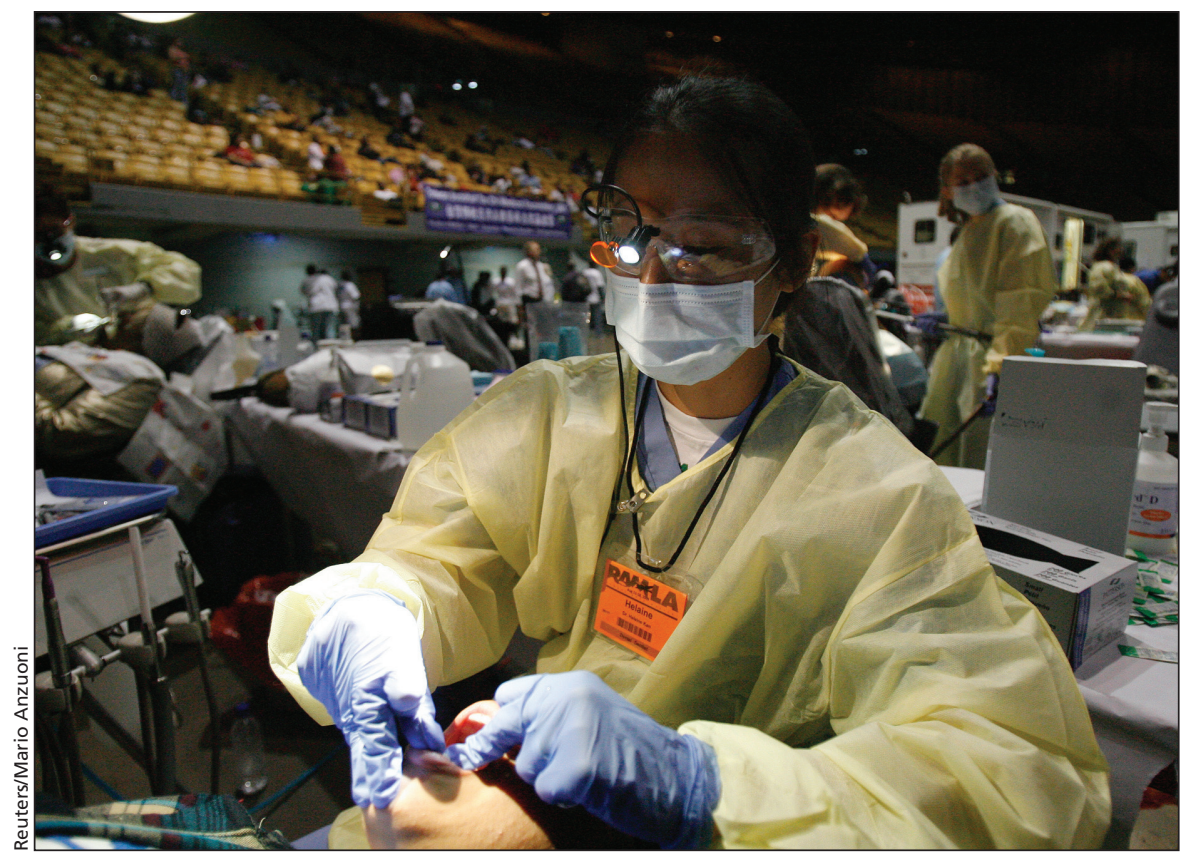

American dentists are often reluctant to open offices in rural areas so many rural residents rely on organizations like the Remote Area Medical Volunteer Corp., which operates clinics, like the one pictured here, in which dentist Helaine Kan works on a patient.

the doors of its dental school, which had been in operation for 107 years.

Though there are still about 700 more dentists entering the field than leaving it each year, the retirement of baby boomer dentists is likely to dramatically change the dental landscape. The American Association of Dental Schools estimates that the number of practising dentists will start to decline as early as 2014. Some states expect to be hit worse than others - and some are already having problems. Kansas, for instance, has dental shortages in 91 of its 105 counties.

"The big issue is we don't have a dental school and we have to recruit from out of state," says Katherine Weno, director of the Bureau of Oral Health for the Kansas Department of Health and Environment, in Topeka. "We have a person on staff who is dedicated exclusively to dental recruitment. We've never had that before."

The biggest problem facing Kansas is the difficulty of attracting dentists to rural areas. The average age of a dentist in the state is 50 , and as older dentists in rural areas retire, fewer younger colleagues are willing to take their place. The state is trying to encourage dentists to work in rural areas by offering to pay their students loans. Of course, the rural dentist shortage problem exists even in states with plenty of dentists, such as California.

"I think a very pertinent question is: Where are the dentists that are already trained?" says Nadereh Pourat, director of research planning for the UCLA (University of California, Los Angeles) Center for Health Policy Research. "In California, there are lots of dentists. It's not that. But often, there are areas where there aren't sufficient numbers of dentists."

In a report released in June, Pourat and a colleague wrote that California, though home to $14 \%$ (31 000) of all US dentists, still has underserved areas 
(www.healthpolicy.ucla.edu/pubs/files /CA_Dentists_FS_061609.pdf).

Statewide, the report states, there are 233 "dental health professional shortage areas," which are defined as areas with a dentist-to-population ratio of one per 5000 or lower. One part of California, Alpine County, has no practising dentist.

California has another big problem, according to Pourat: Nearly half of dentists in the state don't employ a dental hygienist. In a paper published in the Journal of the American Dental Association, Pourat wrote that dentists who employ hygienists are busier and have larger practices (J AM Dent Assoc 2009;140:1027-35). The paper states that dental graduates from other countries and dentists with fewer white patients are less likely to hire hygienists, for reasons such as high costs and insufficient patient volume. "Policies to expand the current dental workforce by training additional dentists and hygienists should take into considera- tion the likelihood that many dentists may not employ hygienists and operate at lower capacity than do those who employ hygienists," Pourat concludes in the report.

Another problem on the dental health front is that some dentists are working fewer hours. This may be due, in part, to the rapid growth in the number of female dentists. According to a 2004 study, female dentists are more likely to work fewer than 32 hours a week than male dentists ( $J$ AM Dent Assoc 2004;135:637-45). In 1982, only $2.6 \%$ of US dentists were female. By 2006 , that had increased to $44.9 \%$.

Dentists are also increasingly choosing to specialize rather than go into general practice. In 1984, about a fifth of dental school graduates went on to become orthodontists or oral surgeons - but now it's closer to a third. Ironically, another potential problem is that baby boomers have healthy teeth. Most will enter retirement with a full set of teeth - unlike any preceding generation - and will therefore require the services of dentists for many years ( $J$ Am Dent Assoc 2000; 131: No suppl_1, 3S-7S).

Canada has similar problems with respect to attracting dentists to rural areas, says Don Friedlander, president of the Canadian Dental Association. Simply turning out more dentists is unlikely to fix rural shortages, he says, suggesting that recruiting dental students from rural areas might be a better approach, in addition to offering incentives to practising dentists to entice them away from urban centres. As for a nationwide shortage of dentists, there is no indication that will happen in Canada, says Friedlander, though he doesn't dismiss the possibility. "Living next to the United States, we know that most of the things that happen across the border usually manifest themselves here." Roger Collier, CMAJ

DOI:10.1503/cmaj.109-3086 